\title{
THE MONOTONE MINORANT METHOD AND EIGENVALUE PROBLEM FOR MULTIVALUED OPERATORS IN CONES
}

\author{
NGUYEN BICH HUY*, TRAN THANH BINH** AND VO VIET TRI*** \\ *Applied Analysis Research Group, Faculty of Mathematics and Statistics \\ Ton Duc Thang University, Ho Chi Minh City, Vietnam \\ E-mail: nguyenbichhuy@tdt.edu.vn \\ **Department of Mathematics and Applications, Sai Gon University \\ 273 An Duong Vuong, Ho Chi Minh City, Vietnam \\ E-mail: tranthanhbinhsgu@gmail.com \\ *** Department of Natural Science, Thu Dau Mot University \\ 6 Tran Van On, Binh Duong province, Vietnam \\ E-mail: trivv@tdmu.edu.vn
}

\begin{abstract}
The main aim of this paper is to obtain a general theorem on existence of continuous branch of solutions of equations which depend on a parameter by using the monotone minorant method in conjunction with the theory of fixed point index. As an application, we apply this theorem to prove the existence of a positive eigen-pair of multivalued homogeneous increasing operators. The simplicity and uniqueness of the eigen-pair are also investigated in this paper.
\end{abstract}

Key Words and Phrases: Cone, positive eigen-pair, fixed point index, monotone minorant, multivalued increasing operator.

2010 Mathematics Subject Classification: 47H04, 47H07, 47H10, 35P30.

Acknowledgements. The authors are very grateful to the referee for his/her careful reading of the work that improve the paper. This paper is funded by Vietnam National Foundation for Science and Technology Development (NAFOSTED) under grant number 101.02-2015.33. The paper was completed when the first author was visitting to Vietnam Institute for Advanced Study in Mathematics (VIASM). He would like to thank the Institue for its hospitality.

\section{REFERENCES}

[1] T. Abdejawad, S.H. Rezapour, Some fixed point results in TVS-cone metric spaces, Fixed Point Theory, 14(2013), no. 2, 265-268.

[2] R.P. Agarwal, D. O'Regan, A note on the existence of multiple fixed points for multivalued maps with applications, J. Differ. Eq., 160(2000), 389-403.

[3] H. Amann, Fixed point equations and nonlinear eigenvalue problems in ordered spaces, SIAM Rev., (1975), 620-709.

[4] A. Bucur, L. Guran, A. Petruşel, Fixed points for multivalued operators on a set endowed with vector-valued metrics and applications, Fixed Point Theory, 10(2009), no. 1, 19-34. 
[5] S. Carl, S. Heikkila, Fixed point theorems for multivalued operators and application to discontinuous quasilinear BVP's, Appl. Anal., 82(2003), 1017-1028.

[6] S. Carl, S. Heikkila, Fixed Point Theory in Ordered Sets and Applications, Springer, Berlin, 2011.

[7] K.C. Chang, A nonlinear Krein-Rutman theorem, Jrl Syst. Sci \& Complexity, 22(2009), 542554 .

[8] K. Deimling, Nonlinear Functional Analysis, Springer, Berlin, 1985.

[9] P.M. Fitzpatrick, W.V. Pettryshn, Fixed point theorems and the fixed point index for multivalued mappings in cones, J. London Math. Soc., 12(1974), 75-85.

[10] S. Hu, N.S. Papageorgiou, Handbook of Multivalued Analysis, vol. I, Kluwer, 1997.

[11] N.B. Huy, Global continua of positive solutions for equations with nondifferentiable operators, J. Math. Anal. Appl., 239(1999), 449-456.

[12] N.B. Huy, N.H. Khanh, Fixed point for multivalued increasing operators, J. Math. Anal. Appl., $\mathbf{2 5 0}(2000), 368-371$.

[13] N.B. Huy, Fixed points of increasing multivalued operators and an application to discontinuous elliptic equations, Nonlinear Anal., 51(2002), 673-678.

[14] M.A. Krasnoselskii, Positive Solutions of Operator Equations, Nordhoff, Groningen, 1964.

[15] R. Mahadevan, A note on a non-linear Krein-Rutman theorem, Nonlinear Anal., 67(2007), 3084-3090.

[16] E.A. Michael, Continuous selections I, Ann. Math., 63(1956), no. 2, 361-382.

[17] J. Mallet-Paret, R.D. Nussbaum, Eigenvalues for a class of homogeneous cone maps arising from max-plus operators, Discrete Continuous Dynamical Systems, 8(2002), 519-562.

[18] D. O'Regan, M. Zima, Leggett-Williams norm-type fixed point theorems for multivalued mappings, Appl. Math. Comput., 187(2007), 1238-1249.

[19] I.R. Petre, Fixed points for $\varphi$-contractions in E-Banach spaces, Fixed Point Theory, 13(2012), no. 2, 623-640.

[20] W.V. Petryshyn, On the solvability of $x \in T x+\lambda F x$ in quasinormal cone with $T$ and $F k$ contractive, Nonlinear Anal., 5(1981), 585-591.

[21] J.R.L. Webb, Remarks on $u_{0}$-positive operators, J. Fixed Point Theory Appl., 5(2009), 37-45.

[22] J.R.L. Webb, G. Infante, Positive solutions of nonlocal boundary value problems: a unifixed approach, J. London Math Soc., 74(2006), no. 2, 673-693.

Received: December 17, 2015; Accepted: April 8, 2016. 
